\title{
Results of early versus standard silicone stent removal following external dacryocystorhinostomy under local anesthesia
}

\author{
Ben Limbu', Benjamin Sim², Mohan K. Shrestha', Geoffrey Tabin², \\ Rohit Saiju' ${ }^{1}$ \\ ${ }^{1}$ Tilganga Institute of Ophthalmology, Kathmandu, Nepal; ${ }^{2}$ Sydney Eye Hospital, \\ Sydney, Australia; ${ }^{3}$ Stanford Byers Eye Institute, Stanford University, Palo Alto, \\ CA, USA
}

\begin{abstract}
Introduction: Many patients in Nepal travel vast distances to have their surgeries in Kathmandu. They often remain close by until their follow-up visit for their silicone tube removal, which contributes to a large financial burden on them and their families. Hence, reducing the time for which silicone tubes remain in situ following external dacryocystorhinostomy (DCR) provides significant benefits to patients. Furthermore, this is the first comparative study which has successfully demonstrated the earliest timeframe for which silicone tubes can be removed following DCR in the medical literature.

Methods: A randomized controlled trial consisting of 144 patients was designed to compare patient outcomes after early (2 weeks postoperatively) versus standard (6 weeks postoperatively) removal of silicone stents. The success of their procedures was determined when patients were assessed both symptomatically and anatomically at their 6-month follow-up.

Results: The surgical success in both groups was high at $97.8 \%$ collectively in both groups and there were only a small number of patients who were lost to follow-up (5 patients) at 6 months. There was no statistical difference at removing silicone stents at 2 or 6 weeks postoperatively.

Conclusion: These results were consistent with our pilot study, which showed no statistical difference in long-term success following silicone tube removal at 2 and 6 weeks.
\end{abstract}

Keywords: dacryocystorhinostomy, nasolacrimal duct obstruction, silicone intubation

\section{Introduction}

Nasolacrimal duct obstruction (NLDO) is a common, often idiopathic condition which causes epiphora and is treated with either an external or endonasal dacryocystorhinostomy (DCR). The use of silicone intubation is common practice in both external and endonasal DCRs; its purpose is presumed to prevent fibrous

Correspondence: Dr. Benjamin Sim, MBBS, MPH, FRANZCO, Sydney Eye Hospital, 8 Macquarie St, Sydney NSW 2000, Australia.

E-mail:01benjaminsim@gmail.com 
closure of the rhinostomy during the postoperative healing period and maintain the patency of the fistula. ${ }^{1}$ We believe that silicone tubing prevents retrograde flow of blood into the canalicular system, which lasts up to 7 days and contributes significantly to fibrosis and subsequent poor results. ${ }^{2}$

The necessity of using silicone tubes following surgery is questionable and, when used, the timing for the duration of its use is controversial. Leaving silicone tubes in situ for an extended period of time does not necessarily confer better postoperative success and doing so can lead to complications such as obstruction from granulation tissue, stenosis and adhesions, bleeding, discomfort, punctal laceration, stent extrusion, and difficult stent removal. The current accepted length of time for silicone stent removal is between 6 weeks and 3 months. In our pilot study, we noted no statistical difference between a small randomized cohort of 50 patients who had their silicone stents removed at 2 and 6 weeks at their 3-month review both symptomatically and anatomically. ${ }^{2}$ In this randomized controlled trial, we compared the anatomical and symptomatic improvement following removal of silicone tubing at 2 and 6 weeks, respectively, at 3 and 6 months.

In Nepal, due to the harsh mountainous terrain and poor transportation infrastructure, patients often travel with their families over vast distances to Kathmandu for their surgeries, leaving their livestock and crops often untended over the span of their surgery and their follow-up review. Not only is there significant expenditure on accommodation and food during their stay, but also a simultaneous loss of income due to not being able to work. Consequently, reducing this social impact became the primary motivation for this study.

Reducing the length of time to remove the silicone stent not only has significant clinical impacts on developing countries like Nepal, where patients travel over large distances for their surgery but also in developed countries. Removing the stent at 2 weeks would reduce complication rates and improve overall patient comfort and satisfaction.

\section{Materials and methods}

This study was a prospective, randomized, masked single-centre study designed to compare the safety and efficacy for the removal of silicone tubing following external DCR surgery for primary NLDO at 2 versus 6 weeks. This study adheres to the guidelines of the Declaration of Helsinki and was approved by the Institutional Review Committee of Tilganga Institute of Ophthalmology.

To determine the sample size for this study, we considered a DCR success rate following stent removal of $94.1 \%$ at 6 weeks and $83.5 \%$ at 2 weeks, a confidence interval of 1.96 , and an $80 \%$ statistical power. Compensating for a $3 \%$ loss to follow-up, we estimated a minimum sample size of 144 patients. The inclusion 
and exclusion criteria for this study were as follows:

Inclusion criteria:

1. age $>16$ years old who can tolerate surgery under local anesthesia; and

2. diagnosis of primary acquired NLDO.

Exclusion criteria:

1. post-traumatic NLDO;

2. redo external DCR surgery;

3. canalicular obstruction $\leq 5 \mathrm{~mm}$; and

4. patients who refused or were unable to undergo surgery under local anesthesia (e.g. mental health issues)

This cohort was then classified by their age (20-39, 40-59, and 60+), gender, and diagnosis (e.g. epiphora, chronic dacryocystitis). Following this, patients were randomized equally into two treatment arms via a sealed envelope method by the timing of their tube removal: early (Group $A$ at 2 weeks) versus standard

Table 1. Clinical features of patients prior to surgery in Groups A and B

\begin{tabular}{|l|l|l|}
\hline Clinical features & Group A & Group B \\
\hline Mean age & 50.2 years (SD: 17.19) & 49.2 years (SD: 16.2) \\
\hline Sex & $\begin{array}{l}\text { Male: } 17(23.6 \%) \\
\text { Female: } 55(76.4 \%)\end{array}$ & $\begin{array}{l}\text { Male: } 13(18 \%) \\
\text { Female: 59 (82\%) }\end{array}$ \\
\hline Mean duration of epiphora & 39.77 months (SD: 48.2) & 35.7 months (SD: 38.8) \\
\hline Mean duration of discharge & 20.8 months (SD: 24.6) & 16.6 months (SD: 19.2) \\
\hline $\begin{array}{l}\text { History of acute } \\
\text { dacryocystitis }\end{array}$ & $5(7 \%)$ & $6(8 \%)$ \\
\hline Duration of mucocele & 13.1 months (SD: 23.2) & 11.4 months (SD: 18.08) \\
\hline Dacryocutaneous fistula & $1(1 \%)$ & $1(1 \%)$ \\
\hline
\end{tabular}

SD: standard deviation

Table 2. Issues noted intraoperatively in Groups A and B

\begin{tabular}{|l|l|l|}
\hline Clinical features & Group A & Group B \\
\hline Sac fibrosis & $2(3 \%)$ & $4(6 \%)$ \\
\hline Sac diverticula & $1(1 \%)$ & $1(1 \%)$ \\
\hline $\begin{array}{l}\text { Inadequate tissue for } \\
\text { anterior/ posterior flap } \\
\text { formation }\end{array}$ & $3(4 \%)$ & $1(1 \%)$ \\
\hline
\end{tabular}




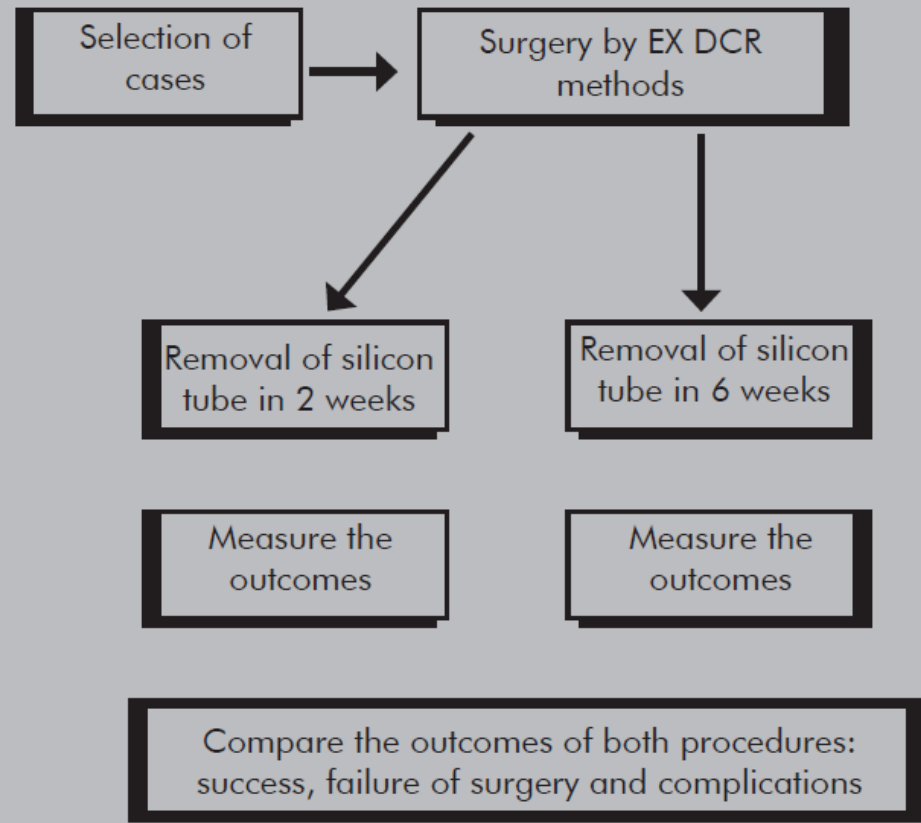

Fig. 1. Research process for the study.

(Group B at 6 weeks). There were 72 patients each in both Groups A and B. Patients with a history of acute dacryocystitis, presence of a mucocele, dacryocutaneous fistula, and sac fibrosis were included in this study and were equally and randomly distributed between the two groups (Tables 1 and 2).

Postoperatively, both groups were followed up at 1 day, 1 week, and at the time of their silicone tube removal, which was either at 2 or 6 weeks postoperatively. Following silicone tube removal, patients were assessed on their degree of symptomatic relief and anatomical patency by independent assessors who were blinded to the nature of the study to reduce observer bias at their 3-and 6-month postoperative visits (Fig. 1).

Surgery was considered successful if the patient had:

1. no watering or occasional watering plus freely patent on irrigation of nasolacrimal apparatus at six months; or

2. partial patency on syringing plus subjectively, no watering at six months. 
Surgery was considered failed if the patient had:

1. complaints of persistent watering and partial patency at 6 months: or

2. complete regurgitation of fluid back to punctum at 6 months regardless of watering.

Data was analyzed using $\mathrm{R}$ Commander ( $\mathrm{R}$ software, version 3.3.2). The chi-squared test was used to evaluate baseline characteristics of the two treatment arms, whilst Fisher's exact test was chosen to assess surgical outcome. A $p$ value of $<0.05$ was considered significant. We also obtained approval from the institutional review board and all patients were consented for their procedures and involvement in the study.

\section{Surgical technique}

All patients underwent a similar surgical procedure by senior oculoplastic surgeons at the Tilganga Institute of Ophthalmology. Preoperatively, intramuscular injection of diclofenac sodium $1.5 \mathrm{mg} / \mathrm{kg}$ was administered to patients. After prepping and draping the surgical area, local anesthetic (2\% lidocaine with adrenaline $1: 10,000$ plus $0.5 \%$ bupivacaine) was injected over the medial canthal tendon area and the nasal edge of the inferior orbital rim. A nasal gauze pack soaked in oxymetazoline $0.05 \%$ plus adrenaline 1:1000 nasal drops was inserted into the ipsilateral nostril. Using a number 15 Bard Parker surgical blade, a straight incision $10 \mathrm{~mm}$ in length was made $10 \mathrm{~mm}$ medial to the medial canthal tendon. The orbicularis muscle was bluntly dissected to expose the medial canthal tendon attachment site and the overlying periosteum. A sufficient flap of periosteum was made after incision near the anterior lacrimal crest. A rectangular-shaped osteotomy of approximately $15 \mathrm{~mm}$ by $15 \mathrm{~mm}$ was made with Kerrison rongeurs. An $\mathrm{H}$-shaped incision at the posterior-inferior lacrimal sac was made, with a long anterior flap and shorter posterior flap. A similar $\mathrm{H}$-shaped incision was made at the nasal mucosa. The posterior flap of the lacrimal sac was trimmed without suturing. Wherever a distal canalicular block was encountered, the probe was more firmly inserted until it was seen in the nasal passage and the common canaliculus was enlarged using a number 11 surgical blade. Subsequently, anterior flap reconstruction using 6-0 vicryl was performed following placement of a silicone tube to stent. Finally, the orbicularis muscle and skin were closed with 6-0 vicryl sutures. Each patient received postoperative nasal packing with gauze soaked in oxymetazoline $0.05 \%$ plus adrenaline 1:1000. Antibiotic ointment along with a cotton gauze was applied over the external wound.

After 30 minutes of observation, patients were discharged with oral antibiotics (ampicillin/cloxacillin 250/250 mg, four times per day) and oral anti-inflammatories (serratiopeptidase, three times per day) for 1 week. Analgesics 
were prescribed as needed and topical antibiotics (ciprofloxacin $0.3 \%$ eye drops, three times per day) were administered.

\section{Results}

Of the 144 patients in this cohort, $142(98.6 \%)$ and 139 patients (96.5\%) were reviewed at their 3- and 6-month follow-up appointments, respectively (Fig. 2). The mean age was 49.7 years (range: $20-89$ years; SD: 16.6). The majority of our participants were female, with a male-to-female ratio of 1:4.8. The percentage of successful operations at the 6-month follow-up was $97 \%$ in Group A and $98.6 \%$ in Group B. The complication rate was $1.4 \%$ in each group at the 6-month follow-up.

This study did not show any statistical difference between silicone tube removal at 2 or 6 weeks following a final assessment at 6 months both from a symptomatic and anatomical point of view. Furthermore, the presence of a history of acute dacryocystitis, presence of a mucocele, dacryocutanenous fistula, or sac fibrosis did not alter this difference in the overall result (Table 3). Both groups studied had minimal complications, with one patient in Group A experiencing tube prolapse which was subsequently removed and one patient in Group B experiencing cheesewiring of their canalicular system (Table 4).

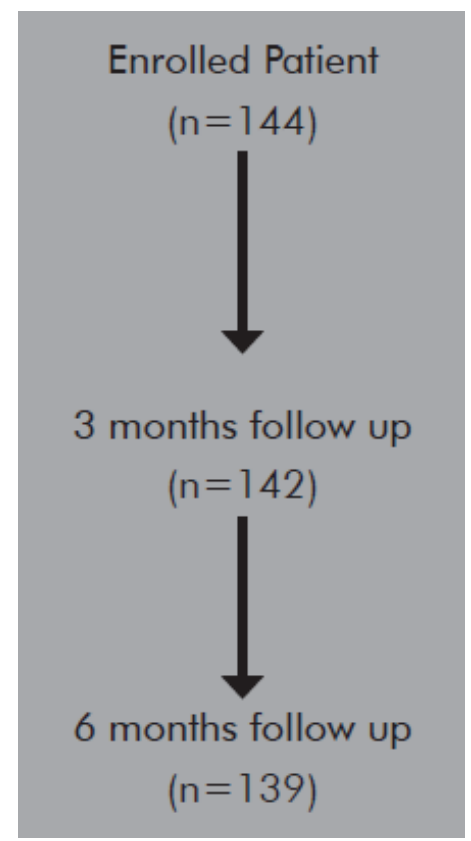

Fig. 2. Number of patients at the start and at the end of the study. 
Table 3. Results of surgical outcome between Groups A and B

\begin{tabular}{|l|l|l|l|l|l|}
\hline \multicolumn{2}{|c|}{ Surgical outcome } & $\begin{array}{l}\text { Group A (Tube } \\
\text { removal at 2 } \\
\text { weeks) }\end{array}$ & $\begin{array}{l}\text { Group B (Tube } \\
\text { removal at 6 } \\
\text { weeks) }\end{array}$ & Total & P-value \\
\hline \multirow{2}{*}{$\begin{array}{l}3 \text { months } \\
(n=142)\end{array}$} & Success & $70(98.6 \%)$ & $70(98.6 \%)$ & $140(98.6 \%)$ & \multirow{2}{*}{1.00} \\
\cline { 2 - 5 } & Failure & $1(1.4 \%)$ & $1(1.4 \%)$ & $2(1.4 \%)$ & \\
\hline \multirow{2}{*}{$\begin{array}{l}6 \text { months } \\
(n=139)\end{array}$} & Success & $68(97 \%)$ & $68(98.6 \%)$ & $136(97.8 \%)$ & 1.00 \\
\cline { 2 - 5 } & Failure & $2(3 \%)$ & $1(1.4 \%)$ & $3(2.2 \%)$ & \\
\hline
\end{tabular}

Table 4. Complication rates between Groups A and B

\begin{tabular}{|l|l|l|l|l|}
\hline $\begin{array}{l}\text { Presence of } \\
\text { complications }\end{array}$ & $\begin{array}{l}\text { Group A (Tube } \\
\text { removal at 2 } \\
\text { weeks) }\end{array}$ & $\begin{array}{l}\text { Group B (Tube } \\
\text { removal at 6 } \\
\text { weeks) }\end{array}$ & Total & P-value \\
\hline $\begin{array}{l}3 \text { months } \\
(n=142)\end{array}$ & $1(1.4 \%)$ & $1(1.4 \%)$ & $2(1.4 \%)$ & 1.00 \\
\hline $\begin{array}{l}6 \text { months } \\
(n=139)\end{array}$ & $1(1.4 \%)$ & $1(1.4 \%)$ & $2(1.4 \%)$ & 1.00 \\
\hline
\end{tabular}

\section{Discussion}

In Nepal, many patients travel large distances over harsh hilly terrain for their surgeries in Kathmandu, which often take many days. As a result, they often stay in Kathmandu from the time of their surgeries until their follow-up, resulting in a loss of income from cessation of work and expenditure to live in the city, which outweighs the cost of their actual surgery. This study was designed to minimize the time taken to remove their silicone tube following DCR surgery, which eventually reduces their follow-up time postoperatively.

The results of this study showed a high success rate following external DCR for all cases $(136$ of $139 ; 97.8 \%)$ at 6 months. This study concludes that early tube removal at 2 weeks showed no statistical difference in the symptomatic and anatomical success as compared to its removal at 6 weeks. The results at 6 months following surgery was consistent with the results of our initial pilot study, which examined a smaller sample size of patients. ${ }^{2}$ The complication rate at the 6 -month mark did not differ in either groups and neither did a history of acute dacryocystitis, presence of a mucocele, dacryocutaneous fistula, and sac fibrosis alter the statistical difference of success in both groups.

The necessity for silicone intubation after a DCR is not universally accepted. While some previous studies and systematic reviews have shown that there is no 
difference with or without the use of silicone tubes in both external and endonasal DCRs, ${ }^{1,3-5}$, others have suggested that its presence improved the overall outcome of the surgery. ${ }^{6,7}$ Silicone tubes have certainly been beneficial in selected situations. Choung et al. ${ }^{4}$ found that silicone tubing can be avoided in $50 \%$ of cases of external DCR, such as in cases with a large lacrimal sac and a wide nasal cavity. Kim et $a l^{8}$ also suggested that silicone intubation is effective when used after cases of external DCR that are anatomically patent but have functionally failed.

When inserted, the silicone tubes have traditionally been placed for 6 weeks to 3 months, with no universally agreed timing for its removal. Its purpose is to prevent fibrous closure while allowing sufficient epithelialization of the rhinostomy and canalicular system during the postoperative healing period, thus maintaining the patency of the fistula. ${ }^{1,9}$ A retrospective study by Charalampidou and Fulcher ${ }^{10}$ revealed that, following external DCR, there was no statistical difference in success between removing silicone tubes before 2 months as compared to between 2-4 months and after 4 months in patients with anatomically confirmed NLDO. This study is the closest comparative study to ours present in the literature to evaluate the efficacy of early stent removal following external DCR. However, it was a retrospective study that did not mention how early the tubes were removed nor did it provide anatomical confirmation of NLD patency in its long-term evaluation. This study has sought to improve on these factors and provide a more definitive evaluation on the topic.

In this prospective randomized study, a high success rate was achieved in all surgeries performed. There was also no statistical difference in the anatomical patency and symptomatic relief to patients following external DCR whether the silicone tube was removed at 2 or 6 weeks, when evaluated at 6 months postoperatively. This is consistent with other studies where early tube removal from spontaneous extrusion, tight tubes, and tube intolerance did not alter the outcome of a successful external DCR procedure. ${ }^{10,11}$

There are no universally agreed upon pathophysiological reasons for the placement of silicone tubes after DCR in the literature to date. From first principles, during the wound healing process, the initial inflammation occurs with clot formation and platelet aggregation, followed by the formation of granulation tissue, proliferation of connective tissue cells, and re-epithelialization of the new tract. During the second week, the leukocytic infiltrate, edema, and increased vascularity largely disappear. ${ }^{12}$ We suggest that the pathophysiological basis for success this early following surgery is that the 2-week period the silicone stents are in place reduces retrograde blood flow into the canalicular system, provides sufficient time for the rhinostomy and canalicular system to re-epithelialize and structurally stabilize, and allows for a reduction in fibrosis and scar formation to remain patent in the long term. ${ }^{2}$ Leaving silicone tubing in situ for an extended 
period of time has also been known to be counterproductive, as silicone is an inorganic surgical material that can lead to numerous complications. These include peripunctal granulation, erosions of puncta and canaliculi, chronic nasal irritation, corneal erosion, canalicular laceration, interpunctal symplepharon, inflammatory mass, and pyogenic granuloma formation. ${ }^{13}$

Finally, the findings of this study positively impact patients who travel long distances for their surgeries - as seen in many developing countries - who experience a significant loss of income and financial burden from living away from their hometowns and villages whilst awaiting their follow-up appointments. Moreover, these results may also benefit patients in developed countries by improving patient comfort and satisfaction with early removal as well as compliance to appointments, ensuring tube removal in cases where patients fail to present for their follow-up for tube removal.

\section{Conclusion}

The findings of this study were consistent with our pilot study, which showed no statistical difference in long-term success following silicone tube removal at 2 and 6 weeks after external DCR. Removing tubes at 2 weeks would avoid a significant financial burden for patients in developing countries as well as improve overall patient satisfaction and reduced complication rates from silicone intubation.

\section{Acknowledgements}

The authors have no conflicts of interest, financial interests, or support or paid consulting to disclose. Himalayan Cataract Project supported this research study.

\section{References}

1. Kang MG, Shim WS, Shin DK, et al. A Systematic Review of Benefit of Silicone Intubation in Endoscopic Dacryocystorhinostomy. Clin Exp Otorhinolaryngol. 2018;11(2):81-88.

2. Limbu B, Lyons HS, Shrestha MK, et al. Comparison of early versus standard timing for silicone stent removal following External Dacrocystorhinostomy under local anaesthesia. Nepal J Ophthalmol. 2019;11(21):24-28.

3. Kashkouli MB, Parvaresh $M$, Modarreszadeh $M$, et al. Factors affecting the success of external dacryocystorhinostomy. Orbit. 2003;22(4):247-255.

4. Choung HK, Khwarg SI. Selective non-intubation of a silicone tube in external dacryocystorhinostomy. Acta Ophthalmol Scand. 2007;85(3):329-332.

5. Feng, YF, Cai, JQ, Zhang, JY, et al. A meta-analysis of primary dacryocystorhinostomy with and without silicone intubation. Can J Ophthalmol. 2011;46:521-527

6. Rather S, Singh T. External dacryocystorhinostomy with \& without silicon tube intubation in chronic dacryocystitis with nasolacrimal duct block. JK Sci. 2013;15:24-27.

7. Xie C, Zhang L, Liu Y, et al. Comparing the Success Rate of Dacryocystorhinostomy With and Without Silicone Intubation: A Trial Sequential Analysis of Randomized Control Trials. Sci Rep. 2017;7(1):1936. 
8. Kim NJ, Kim JH, Hwang SW, et al. Lacrimal silicone intubation for anatomically successful but functionally failed external dacryocystorhinostomy. Korean J Ophthalmol. 2007;21(2):70-73.

9. Buttanri IB, Serin D, Karslioglu S, et al. The outcome of silicone intubation and tube removal in external dacryocystorhinostomy patients with distal canalicular obstruction. Eur J Ophthalmol. 2012;22(6):878-881.

10. Charalampidou S, Fulcher T. Does the timing of silicone tube removal following external dacryocystorhinostomy affect patients' symptoms? Orbit. 2009;28(2-3):115-119.

11. Vicinanzo MG, McGwin G, Boyle M, et al. The consequence of premature silicone stent loss after external dacryocystorhinostomy. Ophthalmology 2008;115(7):1241-1244

12. Kumar V, Abbas AK, Fausto N, et al. Robbins and Cotran pathologic basis of disease. Philadelphia: Elsevier Saunders; 2005.

13. Nuhoğlu F SK, Ozdemir FE. Outcome of External Dacryocystorhinostomy with Bicanalicular Silicone Tube Stenting. JAREM. 2014;4:88-92 